\title{
PROFIL KREATIVITAS ANAK USIA 5-6 TAHUN
}

\author{
Ratih Kusumawardani, Laily Rosidah, \\ Rr. Dina Kusuma Wardhani, \& Reza Mauldy Raharja \\ e-mail: rk.wardani@untirta.ac.id \\ FKIP Universitas Sultan Ageng Tirtayasa
}

\begin{abstract}
Abstrak: Penelitian ini bertujuan untuk mengetahui tingkat kreativitas anak dan efektivitas berbagai model pembelajaran untuk anak usia dini dalam mengembangkan kreativitas anak usia 5-6 tahun di Kota Serang, Banten. Penelitian dilaksanakan pada bulan April hingga Juli 2017. Metode penelitian yang digunakan adalah mixed method dengan populasi penelitian adalah seluruh anak usia 5-6 tahun di Kota Serang, Banten. Sampel penelitian sebanyak 120 anak dari 30 Lembaga PAUD, yang terdiri dari dua kelompok, yaitu 60 anak dari PAUD dengan model pembelajaran berpusat pada guru dan 60 anak dari PAUD dengan model pembelajaran berbasis siswa. Hasil penelitian menunjukkan bahwa tingkat kreativitas anak usia 5-6 tahun di Kota Serang dikategorikan tinggi dan tidak terdapat perbedaan yang signifikan kreativitas anak usia 5-6 tahun pada model pembelajaran berbasis siswa dengan model pembelajaran berpusat pada guru. Namun tingkat kreativitas anak dengan model pembelajaran berbasis siswa lebih tinggi dibandingkan dengan model pembelajaran berpusat pada guru. Penelitian ini menyimpulkan bahwa model pembelajaran berbasis siswa (sentra, area, kelompok, atau sudut) lebih efektif dalam mengembangkan kreativitas anak usia 5-6 tahun. Rekomendasi bagi lembaga, masyarakat, stakeholders, dan peneliti selanjutnya dibahas dalam artikel.
\end{abstract}

Kata-kata kunci: kreativitas anak usia 5-6 tahun, model pembelajaran student centre dan teacher centre

\section{5-6 YEARS CHILDREN CREATIVITY PROFILE}

\begin{abstract}
This study aims to determine the level of child creativity and the effectiveness of various models of learning in early-childhood in developing the creativity of children aged 5-6 years after the city of Serang, Banten. The research was conducted from April to July 2017. The research method used was the mixed method with the research population is all children aged 5-6 years in Serang city, Banten. The sample was 120 children from 30 PAUD institutions, consisting of two groups, which were 60 children from early-childhood with teacher-centered learning model and 60 children from PAUD with student-based learning model. The results showed that the creativity level of children aged 5-6 years in Serang city is categorized as high and there is no significant difference of creativity of children aged 5-6 years after the model of student-based learning with teacher-centered learning model. However, the level of creativity of children with student-based learning model is higher than the teacher-centered learning model. This study concludes that student-based learning model (center, area, group, or angle) is more effective in developing the creativity of children aged 5-6 years. Recommendations for institutions, communities, stakeholders, and researchers are further discussed within the article.
\end{abstract}

Keywords: 5-6 years children creativity, student-based learning and teacher-centered learning model

\section{PENDAHULUAN}

Teori kebutuhan Maslow (Rawat, 2016) menyatakan bahwa kreativitas merupakan salah satu kebutuhan manusia yang termasuk dalam level paling puncak, yaitu kebutuhan dalam aktualisasi diri. Melalui kreativitas, seseorang dapat mewujudkan dirinya, dapat memecahkan berbagai permasalahan, memberikan kepuasaan, bahkan meningkatkan kualitas hidupnya. Hal ini juga senada dengan pernyataan Kartadinata (2012), bahwa salah satu keterampilan yang harus dikuasai di abad 21 adalah kemampuan dalam berpikir, yaitu berpikir kreatif dan inovatif, berpikir kritis, memecahkan masalah, membuat keputusan, belajar untuk belajar, dan metakognisi. 
Polar kritis dalam kehidupan manusia adalah masa usia dini yang apabila berbagai potensi tumbuh kembang secara optimal dapat menjadi salah satu penentu masa dewasa. Demikian juga dengan potensi kreatif, anak yang kreatif akan menjadi manusia dewasa yang kreatif yang mampu menghasilkan banyak karya yang berguna bagi kehidupan manusia.

Permasalahan yang mendasar dalam pengembangan kreativitas adalah dibatasinya kreativitas anak dengan memberikan kegiatankegiatan otak kiri yang bersifat akademik dan skolastik. Fenomena membaca, menulis, dan berhitung yang banyak diberikan kepada anak melalui kegiatan akademik sedini mungkin, membuat anak usia 5-6 tahun banyak diberikan kegiatan pencil and paper task, berhitung abstrak, dan membaca dengan cara dilatih (drill). Hal ini tentu saja menunjukkan bahwa lembaga PAUD tidak memberikan kesempatan anak untuk bermain, bereksplorasi, berimajinasi, dan berinteraksi dengan lingkungan pembelajaran yang kaya, sehingga kreativitas anak dibatasi. Pembelajaran seperti ini disebut juga dengan pembelajaran yang berpusat pada guru (teacher centre).

Menurut Sternberg (2006), kreativitas membutuhkan kerjasama dari kemampuan intelektual, pengetahuan, gaya berpikir, kepribadian, motivasi, dan lingkungan. Kreativitas anak menurut penelitian Peningkatan Kreativitas melalui Pendekatan Brain Based Learning (Kusumawardani 2015) adalah "Proses kognitif yang muncul dari aspek 4P, yaitu pribadi, pendorong, proses dan produk. Keempat aspek itu adalah (1) aspek pribadi, yaitu menggambarkan aspek kelancaran (fluency), kelenturan (flexibility), orisinalitas (originality), kerincian (elaboration), dan kepekaan (sensitivity) dengan karakteristik anak bertanya, tertarik dengan banyak kegiatan, mencoba hal-hal baru, menjelajah lingkungan sekolah, mudah beradaptasi dengan perubahan situasi, terlihat bebas dalam melakukan berbagai hal, terbuka terhadap hal baru, melakukan kegiatan dengan cara yang berbeda dari temannya, memiliki banyak jawaban terhadap satu pertanyaan, mencoba hal-hal sulit, mengungkapkan pendapat terhadap sebuah masalah, dan memperlihatkan selera humor; (2) aspek pendorong, yaitu anak melakukan kegiatan atas keinginan sendiri, dan terlihat bersemangat dan antusias dalam melakukan berbagai kegiatan di sekolah; (3) aspek proses, yaitu keterlibatan aktif anak dalam berbagai kegiatan di sekolah, baik kegiatan individu maupun kegiatan kelompok; dan (4) aspek produk yang berupa berupa model, tindakan, gerakan, kata-kata, melodi, bentuk, atau karya lainnya". Keempat aspek kreativitas ini sangat penting dalam perkembangan kreativitas karena anak yang kreatif harus memiliki keempat aspek kreativitas, pribadi yang kreatif jika didorong dalam proses kreatif akan menghasilkan produk kreatif (Kusumawardani, 2015). Karakteristik kreativitas anak usia dini yang dipaparkan di atas selanjutnya akan menjadi indikator dalam instrumen kreativitas dalam penelitian ini.

Orisinalitas adalah nilai utama dalam penelitian kreativitas (Runco and Jaeger, 2012). Namun, menurut Runco (1988), standar dari pengertian kreativitas adalah orisinalitas yang harus diseimbangkan dengan kepantasan (fit and appropriateness). Pernyataan Runco ini memperkuat konsep kreativitas, bahwa kreativitas tidak sekedar menghasilkan ide atau gagasan baru tetapi harus memiliki nilai kepantasan dan manfaat. Banyak pendekatan yang dapat dilakukan oleh Lembaga PAUD dalam mengakomodir kebutuhan perkembangan anak, dalam hal ini adalah kreativitas. Lembaga PAUD dapat menerapkan berbagai model pembelajaran yang mampu mengakomodir perkembangan kreativitas anak. Wilma (2000) mengatakan model pembelajaran yang diterapkan pada anak usia dini harus memperhatikan prinsip belajar sambil bermain, kreatif dan inovatif, lingkungan kondusif, tema, mengembangkan keterampilan, menggunakan pembelajaran terpadu, dan pembelajaran berorientasi pada prinsip.

Permendikbud No.146 Tahun 2014 tentang kurikulum Pendidikan Anak Usia dini menjelaskan tentang bagaimana merencanakan dan mengelola kelas. Pengelolaan kelas disesuaikan dengan model-model pembelajaran tersebut, seperti (1) model pembelajaran kelompok berdasarkan sudutsudut kegiatan, (2) model pembelajaran kelompok berdasarkan kegiatan pengaman, (3) model pembelajaran berdasarkan area (minat), dan (4) model pembelajaran berdasarkan sentra.

Model pembelajaran yang menggunakan model sudut, kelompok, area, atau sentra disebut dengan model pembelajaran student centre pada penelitian ini. Model pembelajaran student centre merupakan salah satu model pembelajaran yang membuat anak menjadi pusat pembelajaran 
dan pengetahuan. Anak diharapkan lebih aktif untuk bereksplorasi dengan lingkungannya untuk mendapatkan pengetahuan dan keterampilan. Peran guru dalam model pembelajaran student centre adalah sebagai fasilitator, motivator, dan evaluator, bukan satu-satunya sumber informasi.

Pembelajaran menurut Sadiman (1990) adalah usaha-usaha terencana dalam memanipulasi sumber-sumber belajar agar terjadi proses belajar dalam peserta didik. Salah satu cara mengukur pembelajaran yang efektif yaitu dengan melakukan perbandingan antara rencana pembelajaran dengan tujuan pembelajaran itu sendiri. Pembelajaran yang efektif merupakan pembelajaran yang menyediakan kesempatan belajar sendiri atau melakukan aktivitas sendiri (Hamalik, 2005).

\section{METODE PENELITIAN}

Penelitian ini menggunakan mixed methods yang mengkombinasikan metode kuantitatif dengan kualitatif untuk digunakan secara bersama-sama dalam suatu kegiatan penelitian, sehingga diperoleh data yang lebih komprehensif, valid, reliabel, dan objektif.

Populasi dalam penelitian ini adalah seluruh anak usia 5-6 tahun di kota Serang, Banten. Sampel ditentukan menggunakan teknik Proportionate Stratified Random Sampling karena populasi bersifat heterogen, sehingga harus dibagi dalam strata-strata yang homogen dan dari setiap strata diambil sampel proporsional secara acak (Kasjono \& Yasril, 2009;
Nurhayati, 2008). Berdasarkan hasil perhitungan, dari 30 PAUD diperoleh 120 anak sebagai sampel. Sampel ini terdiri dari 60 anak dari PAUD dengan model pembelajaran student centre dan 60 anak dari PAUD dengan model pembelajaran teacher centre.

Pengumpulan data kreativitas anak dilakukan dengan teknik kuesioner, catatan lapangan, catatan wawancara, dan dokumentasi. Tingkat kreativitas diukur dengan statistik deskriptif sesuai dengan skor yang diperoleh dari angket kreativitas. Efektivitas diukur dengan menggunakan uji beda kreativitas lalu dianalisis secara kualitatif.

\section{HASIL DAN PEMBAHASAN}

\section{Tingkat kreativitas anak usia 5-6 tahun}

Tingkat kreativitas anak usia 5-6 tahun di kota Serang, Banten diperoleh dari data berupa skor kreativitas anak usia 5-6 tahun menggunakan skala Likert. Indikator yang digunakan dalam instrumen penelitian kreativitas anak usia 5-6 tahun seperti terlihat pada Tabel 1.

Tabel 1

Indikator Kreativitas Anak Usia 5-6 Tahun

\begin{tabular}{|c|c|}
\hline No. & Indikator \\
\hline 1 & Anak bertanya \\
\hline 2 & Anak memiliki daya imajinasi \\
\hline 3 & $\begin{array}{l}\text { Anak hanya tertarik dengan hal/kegiatan yang } \\
\text { itu-itu saja }\end{array}$ \\
\hline 4 & Anak mencoba hal-hal baru \\
\hline 5 & Anak bereksplorasi \\
\hline 6 & $\begin{array}{l}\text { Anak tidak mampu mengatasi perubahan situasi } \\
\text { yang terjadi }\end{array}$ \\
\hline 7 & $\begin{array}{l}\text { Anak tidak berminat dalam melakukan berbagai } \\
\text { hal/kegiatan }\end{array}$ \\
\hline 8 & Anak sulit untuk berkompromi \\
\hline 9 & $\begin{array}{l}\text { Anak melakukan kegiatan yang unik dengan } \\
\text { caranya sendiri }\end{array}$ \\
\hline
\end{tabular}

\begin{tabular}{ll}
\hline No. & \multicolumn{1}{c}{ Indikator } \\
\hline 10 & $\begin{array}{l}\text { Anak melakukan kegiatan yang sama dengan } \\
\text { temannya }\end{array}$ \\
11 & Anak berpendirian kuat \\
12 & $\begin{array}{l}\text { Anak melihat suatu masalah dari berbagai sudut } \\
\text { pandang }\end{array}$ \\
13 & Anak lebih suka melakukan hal-hal yang mudah \\
14 & Anak memperlihatkan rasa seni \\
15 & $\begin{array}{l}\text { Anak sulit mengungkapkan pendapat terhadap } \\
\text { sebuah masalah/kejadian }\end{array}$ \\
16 & $\begin{array}{l}\text { Anak melakukan kegiatan setelah diberikan } \\
\text { motivasi }\end{array}$ \\
17 & Anak memiliki selera humor yang tinggi \\
\hline
\end{tabular}

Untuk menentukan tingkat kreativitas anak usia 5-6 tahun di kota Serang, digunakan daftar konsultasi WMS sebagi acuan skor rata-rata tingkat kreativitas anak seperti terlihat pada Tabel 2.

Tabel 2

Daftar Konsultasi WMS

\begin{tabular}{ccc}
\hline $\begin{array}{c}\text { Rentang } \\
\text { Nilai }\end{array}$ & Kriteria & $\begin{array}{c}\text { Penafiran } \\
\text { Pernyataan Positif }\end{array}$ \\
\hline $3,01-4,00$ & Sangat Tinggi & S (Selalu) \\
\hline
\end{tabular}




\begin{tabular}{cll}
\hline $\begin{array}{c}\text { Rentang } \\
\text { Nilai }\end{array}$ & \multicolumn{1}{c}{ Kriteria } & \multicolumn{1}{c}{$\begin{array}{c}\text { Penafiran } \\
\text { Pernyataan Positif }\end{array}$} \\
\hline $2,01-3,00$ & Tinggi & SR (Sering \\
$1,01-2,00$ & Rendah & JR (Jarang) \\
$0,01-1,00$ & Sangat Rendah & TP (Tidak Pernah) \\
\hline
\end{tabular}

Data tentang tingkat kreativitas anak usia 5-6 tahun di Kota Serang berdasarkan skor rata-rata yang dikonsultasikan dengan tabel WMS, seperti terlihat pada Tabel 3 .

Tabel 3

Skor Kecenderungan Rata-Rata

Kreativitas Anak Usia 5 - 6 Tahun

\begin{tabular}{|c|c|c|c|c|}
\hline No. & Indikator & No. Item & Mean & Kategori \\
\hline \multirow[t]{11}{*}{1} & Pernyataan & 1 & 3,13 & Sangat Tinggi \\
\hline & & 2 & 2,85 & Tinggi \\
\hline & & 4 & 3,13 & Sangat Tinggi \\
\hline & & 5 & 3,08 & Sangat Tinggi \\
\hline & & 8 & 2,00 & Rendah \\
\hline & & 9 & 3,07 & Sangat Tinggi \\
\hline & & 11 & 3,12 & Tinggi \\
\hline & & 12 & 2,65 & Tinggi \\
\hline & & 14 & 2,89 & Tinggi \\
\hline & & 17 & 2,45 & Tinggi \\
\hline & Rata-rata & & 2,84 & Tinggi \\
\hline \multirow[t]{8}{*}{2} & Pernyataan & 3 & 2,98 & Tinggi \\
\hline & & 6 & 2,91 & Tinggi \\
\hline & & 7 & 3,16 & Sangat Tinggi \\
\hline & & 10 & 2,02 & Tinggi \\
\hline & & 13 & 2,28 & Tinggi \\
\hline & & 15 & 2,85 & Tinggi \\
\hline & & 16 & 2,08 & Tinggi \\
\hline & Rata-rata & & 2,61 & Tinggi \\
\hline
\end{tabular}

Skor rata-rata kreativitas dari model pembelajaran student centre dengan model pembelajaran teacher centre dapat dilihat pada Tabel 4 dan Tabel 5.

Tabel 4

Skor Rata-Rata Kreativitas Anak dengan Model Teacher Centre

\begin{tabular}{clcrl}
\hline No. & Indikator & No. Item & Mean & Kategori \\
\hline 1 & Pernyataan & 1 & 3,00 & Tinggi \\
& Positif & & & \\
& & 2 & 2,66 & Tinggi \\
& & 4 & 3,11 & Sangat Tinggi \\
\hline
\end{tabular}

\begin{tabular}{|c|c|c|c|c|}
\hline No. & Indikator & No. Item & Mean & Kategori \\
\hline & & 5 & 2,91 & Sangat Tinggi \\
\hline & & 8 & 1,98 & Rendah \\
\hline & & 9 & 2,95 & Sangat Tinggi \\
\hline & & 11 & 2,96 & Tinggi \\
\hline & & 12 & 2,33 & Tinggi \\
\hline & & 14 & 2,76 & Tinggi \\
\hline & & 17 & 2,30 & Tinggi \\
\hline & Rata-rata & & 2,70 & Tinggi \\
\hline \multirow[t]{8}{*}{2} & $\begin{array}{l}\text { Pernyataan } \\
\text { Neqatif }\end{array}$ & 3 & 3,06 & Sangat Tinggi \\
\hline & & 6 & 3,05 & Sangat Tinggi \\
\hline & & 7 & 3,23 & Sangat Tinggi \\
\hline & & 10 & 2,20 & Tinggi \\
\hline & & 13 & 2,26 & Tinggi \\
\hline & & 15 & 2,96 & Tinggi \\
\hline & & 16 & 1,98 & Rendah \\
\hline & Rata-rata & & 2,68 & Tinggi \\
\hline
\end{tabular}

Tabel 5

Skor Rata-Rata Kreativitas Anak dengan Model Student Centre

\begin{tabular}{|c|c|c|c|c|}
\hline No. & Indikator & No. Item & Mean & Kategori \\
\hline \multirow[t]{11}{*}{1} & Pernyataan & 1 & 3,26 & Sangat Tinggi \\
\hline & & 2 & 3,31 & Sangat Tinggi \\
\hline & & 4 & 3,20 & Sangat Tinggi \\
\hline & & 5 & 3,25 & Sangat Tinggi \\
\hline & & 8 & 2,03 & Tinggi \\
\hline & & 9 & 2,93 & Tinggi \\
\hline & & 11 & 3,28 & Sangat Tinggi \\
\hline & & 12 & 2,98 & Tinggi \\
\hline & & 14 & 3,01 & Sangat Tinggi \\
\hline & & 17 & 2,61 & Tinggi \\
\hline & Rata-rata & & 2,99 & Tinggi \\
\hline \multirow[t]{8}{*}{2} & Pernyataan & 3 & 2,90 & Tinggi \\
\hline & & 6 & 2,78 & Tinggi \\
\hline & & 7 & 3,10 & Sangat Tinggi \\
\hline & & 10 & 1,85 & Rendah \\
\hline & & 13 & 2,30 & Tinggi \\
\hline & & 15 & 2,75 & Tinggi \\
\hline & & 16 & 2,18 & Tinggi \\
\hline & Rata-rata & & 2,55 & Tinggi \\
\hline
\end{tabular}

Berdasarkan Tabel 3,4, dan 5 terlihat bahwa kreativitas anak usia 5-6 tahun baik dari PAUD dengan model pembelajaran student centre maupun teacher centre memiliki tingkat kreativitas 
yang tinggi. Hal ini terlihat dari sebagian besar indikator kreativitas anak usia 5-6 tahun memiliki skor yang tinggi hingga sangat tinggi. Pada model pembelajaran student centre skor kreativitas yang rendah hanya muncul pada indikator nomor 10 , sedangkan pada model pembelajaran teacher centre skor rendah ada pada dua indikator yaitu, nomor 8 dan 16.

\section{Efektivitas Berbagai Model Pembelajaran Anak Usia Dini yang Diterapkan dalam Mengembangkan Kreativitas Anak Usia 5-6 Tahun di Kota Serang Banten}

Uji beda tahap ini adalah uji beda kreativitas model pembelajaran student centre dan teacher centre menggunakan $t$-test berkorelasi dengan membandingkan dua kelompok, maka digunakan $t$ - test sampel related. Hasil pengujian seperti terlihat pada Tabel 6.

Tabel 6

Group Statistics

\begin{tabular}{llllll}
\hline & Jenis & N & Mean & $\begin{array}{l}\text { Std. De- } \\
\text { viation }\end{array}$ & $\begin{array}{l}\text { Std. } \\
\text { Error } \\
\text { Mean }\end{array}$ \\
\hline $\begin{array}{l}\text { Dimen- } \\
\text { sion }\end{array}$ & 1 & 120 & 23.0250 & 5.83450 & .53261 \\
& 2 & 120 & 24.0667 & 7.31837 & .66807 \\
\hline
\end{tabular}

Hasil nilai t-hitung adalah -1,219 dan signifikansinya 0,00 . Melalui hasil tersebut dan dikonsultasikan dengan nilai t-tabel dimana nilai t-tabel adalah 1,645 sedangkan t-hitung lebih kecil dari pada t-tabel, maka kesimpulan dapat dibuat adalah menolak $\mathrm{H}_{\mathrm{a}}$ dan menerima $\mathrm{H}_{\mathrm{o}}$ yang berarti tidak ada perbedaan antara metode teacher centre dengan metode student centre dalam mengembangkan kreativitas anak usia 5-6 tahun di kota Serang, Banten.

Efektivitas model pembelajaran terhadap kreativitas dianalisis secara kualitatif berdasarkan data catatan lapangan, catatan wawancara, dan dokumentasi dari kreativitas anak dan model pembelajaran di 30 PAUD.

Model pembelajaran teacher centre yang dimaksud dalam penelitian ini adalah model pembelajaran sentra, area, dan kelompok sedangkan, model pembelajaran student centre yang dimaksud adalah model pembelajaran klasikal di mana guru menjadi pusat pembelajaran dengan tugas-tugas yang sama untuk semua anak dalam satu waktu. Baik model pembelajaran teacher centre maupun student centre menunjukkan kreativitas yang tinggi pada anak usia 5-6 tahun di Kota Serang, Banten. Semua indikator kreativitas muncul pada anak saat pembelajaran. Hal ini terlihat dari catatan lapangan bahwa anak-anak memunculkan beberapa indikator kreativitas di sekolah. Pada catatan wawancara diperoleh data dari kepala sekolah atau guru bahwa model pembelajaran yang diterapkan di PAUD sudah mampu mengoptimalkan kreativitas anak.

Namun, kepala sekolah atau guru dari model pembelajaran student centre menjelaskan bahwa model pembelajaran student centre mampu mengembangkan kreativitas anak lebih optimal daripada model pembelajaran teacher centre. Hal ini juga semakin diperkuat oleh pernyataan dari para kepala sekolah dan guru yang sebelumnya pernah menerapkan model pembelajaran teacher centre. Bermain menjadi salah satu kunci berkembangnya kreativitas anak dalam model pembelajaran student centre, karena saat bermain, anak berekplorasi untuk membangun pengetahuan dengan cara yang menyenangkan. Hal ini diperkuat oleh pernyataan Fauzi (2016) bahwa salah satu karakter yang dibangun dalam bermain adalah karakter kreatif.

Berdasarkan analisis dari ketiga data berupa catatan lapangan, catatan wawancara, dan dokumentasi dapat disimpulkan bahwa baik model pembelajaran teacher centre maupun student centre mampu mengembangkan kreativitas anak dengan baik. Namun, model pembelajaran student centre lebih efektif dalam mengoptimalkan kreativitas anak usia 5-6 tahun. Hal ini dapat terlihat dari ratarata skor kreativitas anak dari model pembelajaran student centre yang lebih tinggi dibandingkan kreativitas anak dari model pembelajaran teacher centre.

\section{PENUTUP}

\section{Kesimpulan}

Anak adalah manusia kreatif yang harus terus diberikan stimulasi agar dapat manjadi manusia dewasa yang kreatif di masa depan. Lembaga PAUD memegang peran penting sebagai lembaga pendidikan yang pertama dan paling penting dalam 
masa keemasan anak. Menerapkan pembelajaran yang sesuai dengan tahapan perkembangan anak, fitrah anak, dan model pembelajaran yang tepat menjadi wajib untuk dilaksanakan di Lembaga PAUD. Semakin dini anak-anak diberikan lingkungan yang membuat menjadi kreatif, semakin optimal perkembangan kreativitas anak.

\section{Saran}

Penelitian ini diharapkan bermanfaat bagi lembaga PAUD agar menerapkan model pembelajaran yang berpusat pada anak untuk mengoptimalkan potensi kreativitas anak usia dini. Masyarakat juga diharapkan semakin paham bahwa pendidikan anak usia dini tidak semata menghasilkan anak yang cerdas secara akademik, tetapi juga anak yang kreatif. Terakhir, stakeholder diharapkan lebih mendukung lembaga PAUD untuk menerapkan pembelajaran yang berpusat pada anak, baik itu melalui kebijakan, pendampingan, pelatihan, maupun pengawasan.

\section{DAFTAR PUSTAKA}

Depdikbud. (2014). Permendikbud nomor 146 Tahun 2014 tentang kurikulum 2013 pendidikan anak usia dini. Jakarta.

Fauzi. (2016). Pembentukan karakter anak melalui permainan tradisional cim-ciman. Jurnal IImiah VISI PPTK-PAUDNI, 11(2), 99-110. doi: 10.21009/JIV.1102.4

Kartadinata, S. (2012). Memantapkan karakter bangsa menuju generasi 2045. Seminar Nasional Peringatan Hari Guru, 25 November 2012.

Kasjono, H. S. \& Yasril. (2009). Teknik sampling untuk penelitian kesehatan. Yogyakarta: Graha IImu.

Kusumawardani, R. (2015). Peningkatan kreativitas melalui pendekatan brain based learning. Jurnal Pendidikan Usia Dini, 9(1), 143-162. doi: 10.21009/JPUD.091.09

Nurhayati. (2008). Studi perbandingan metode sampling antara simple random dengan stratified random. Jurnal Basis Data, 3(1), 18-32. http://old.unas.ac.id/download. php?file=Basis_Data_Vol_3_No_1_2008_ list3.pdf
Hamalik, O. (2005). Proses belajar mengajar. Bandung: PT. Remaja Rosdakarya.

Rawat, A. (2016). Assessing the needs of the learner through maslow's model of self-actualization. The International Journal of Humanities \& Social Studies, 4(10), 132-135. http://theijhss. com/2016-2/october-16

Runco, M.A. (1988). Creativity research: originality, utility, and integration. Creativity Research Journal, 1(1), 1-7. doi: 10.1080/10400418809534283

Runco, M.A., \& Jaeger, G.J. (2012). The standard definition of creativity. Creativity Research Journal, 24(1,) 92-96. doi: 10.1080/10400419.2012.650092

Sadiman, A.S. (1990). Media pendidikan, pengertian, pengembangan, dan pemanfaatannya. Jakarta: CV Rajawali.

Sternberg, R.J. (2006). The nature of creativity. Creativity Research Journal, 18(1), 87-98. doi: 10.1207/s15326934crj1801_10

Wilma, V., et al. (2000). Handbook on child development. Australia: Social Science Press. 